\title{
Sunset clauses: a contribution to legislative quality
}

By Prof. Helen Xanthaki ${ }^{1}$

\section{A. Hypothesis and method}

Current analysis on sunset clauses tends to focus on constitutional aspects of their utility, their usage, its advantages and its inherent dangers. ${ }^{2}$ Little, if any, analysis looks at their role in legislative drafting, both as carriers of a regulatory message and as technical legislative provisions. This chapter aims to address both sets of issues, by defining sunset clauses, placing them in the realm of duration or time provision, addressing their drafting requirements, and discussing their role as contributors and supervisors of legislative effectiveness.

Legislative effectiveness is embraced as synonymous to, or a measure of, legislative quality by international and national lawmakers, and academic and professional drafters. ${ }^{3}$

The hypothesis of this paper is that sunset clauses contribute to legislative effectiveness and regulatory efficacy. In order to prove this hypothesis, the chapter begins by defining and analysing sunset clauses as a legislative tool. It proceeds with the analysis of legislative effectiveness, and the identification of the role of sunset clauses as contributors to legislative

\footnotetext{
${ }^{1}$ Prof. Helen Xanthaki, LLB (Ath), MJur, PhD (Dunelm), SFHEA, is Professorial Teaching Fellow and Hon. Professor, UCL, and Visiting Professor, QMUL; Director of PGLaws Programmes, University of London; Senior Research Fellow, IALS; and President of the International Association for Legislation.

${ }^{2}$ See Antonios Kouroutakis, Sunset Clauses: A Historical, Positive and Normative Analysis (2014) PQDT - UK \& Ireland; also see Alli Sutherland, "Ghosting in Tax Law: Sunset Provisions and Their Unfaithfulness" [20182019] 46 Hastings Constitutional Law Quarterly 479, 498; John Ip, "Sunset Clauses and Counterterrorism Legislation" [2013] Public Law 74, 75; Dan Price, "Sunset Legislation in the United States" [1978] 30 Baylor Law Review 401.

${ }^{3}$ See Helen Xanthaki, “'The Problem of Quality in EU Legislation: What on Earth is Really Wrong?” [2001]

38 Common Market Law Review 651, 660; also see Wim Voermans, "Concern About the Quality of EU Legislation: What Kind of Problem, by What Kind of Standards?" [2009] 2 Erasmus Law Review 59, 62; Claudio Radaelli and Franko de Francesco, Regulatory Quality in Europe: Concepts, Measures and Policy Processes (2007, Manchester University Press, Manchester) 37; C. Veljanovski, "Economic Approaches to Regulation" in R. Baldwin, M. Cave and M. Lodge, The Oxford Handbook of Regulation (2010, Oxford University Press, Oxford), 19; European Commission, 'European Governance: Better lawmaking' (Communication) COM (2002) 275 final; EP, Council, Commission, Interinstitutional Agreement on better lawmaking [2003] Official Journal of the European Union C C321/1, point 25, http://eurlex.europa.eu/LexUriServ/LexUriServ.do?uri=CELEX:32003Q1231\%2801\%29:EN:NOT; UK OPC, Drafting Guidance, 2017, https://www.gov.uk/government/uploads/system/uploads/attachment_data/file/666328/drafting_guidance_Dec_ 2017.pdf; Australian OPC, Reducing complexity in legislation, June 2016, http://www.opc.gov.au/about/docs/ReducingComplexity.pdf; Government of Canada, Guide to Making Federal Acts and Regulations, 2001, http://www.pco.gc.ca/docs/information/publications/legislation/pdf-eng.pdf.
} 
quality. It continues with the presentation of Xanthaki's enlightened scrutiny test, and the identification of the role of sunset clauses as guardians of legislative quality. And it concludes by proposing the extended use of sunset clauses as contributors to legislative quality and guardians of regulatory efficacy even beyond short-term legislative texts ${ }^{4}$.

\section{B. Sunset clauses: a legislative exploration}

The start and end of the life of legislation is expressed in duration provisions. The latter convey to the user when their obligation to comply with the legislation begins, and when it ends. Duration provisions is a term that encompasses both commencement and expiry provisions. They address the issue of time related to the legislative text itself. Thus, they differ from retroactive and retrospective provisions that address time related to the regulation expressed by the text. Duration provisions relate to the technical, administrative aspect of time in legislation, whereas retroactive and retrospective provisions relate to the substantive aspect of time in law. ${ }^{5}$

The start of life of legislation is expressed in commencement provisions, namely provisions that set the date when legislation begins to have effect. They do not set the time of passing of the legislation but their time of coming into force. This is the moment that they draw their first breath as part of the system of law of the jurisdiction where they belong. In the UK commencement provisions are now known simply as the start date of the legislative text. The need to use a more user-friendly term for commencement came up in the Good Law survey of the UK's Office of Parliamentary Counsel, where iris tracking of legislative users revealed their immense puzzlement over where to find commencement, what it meant, and how it related to the rest of the legislative text. The term has become accepted in the UK but has not caught up in the rest of the Commonwealth, where commencement is commonly used. This is perhaps a reflection of the continued common law tradition of complex and technical start dates subject to a notification from a Minister.

\footnotetext{
${ }^{4}$ One of the most prominent authors supporting the use of sunset clauses in emergencies is Prof. Ackerman: see Bruce Ackerman, “The Emergency Constitution” [2004] 113 Yale Law Journal 1029.

${ }^{5}$ It is worth noting here, however, that substance and form are not completely disconnected. It is argued that sunset clauses may end the form, the legislation, but not the regulation. Legislation may well continue to produce effects after the expiry of the legislation, because it may affect compliance behaviour that goes beyond statutory enforcement. See Frank Fagan, "After the Sunset: The Residual Effect of Temporary Legislation" [2013] 36 European Journal of Law and Economics 209-226.
} 
The end of life of legislation is expressed in expiry provisions, namely provisions that set the date when legislation ceases to have effect. ${ }^{6}$ A relatively recent example of a UK expiry provision is found in the Armed Forces Act 2006:

This Act expires at the end of one year beginning with the day on which the Armed Forces Act 2016 is passed (but this is subject to subsection (2)).

Research in the UK statute book via www.legislation.gov.uk shows 19 Acts carrying expiry provisions. $^{7}$

From a legislative perspective, sunset clauses are a subcategory of expiry provisions. Sunset clauses declare that the Act, at a set time, 'ceases to have effect unless it is reauthorized". They are defined as "A provision in a Bill that gives it an expiry date once it is passed into law. Sunset clauses are included in legislation when it is felt that Parliament should have the chance to decide on its merits again after a fixed period." 9 Thus, sunset clauses are a complex sub-category of expiry provisions, which introduce two regulatory messages: first, the end of life of legislation at a set time; and second, conditional upon a decision of Parliament, hopefully made on the basis of post-legislative scrutiny. ${ }^{10}$ In recent literature, sunset clauses are mentioned as a tool to adopt a constitution "on an interim basis, pending its promulgation after a five-year period of correction and further opportunities for public consultation" 11 ; or as tools for institutional reform in post-conflict power-sharing arrangements ${ }^{12}$; or as a mechanism

\footnotetext{
${ }^{6}$ See Helen Xanthaki, "Legislative Techniques in Rwanda: Present and Future" [2013] 15 European Journal of Law Reform 95, 156.

${ }^{7}$ See Armed Forces Act 2016; Debt Relief (Developing Countries) Act 2010; Crofting Reform (Scotland) Act 2010; Holocaust (Return of Cultural Objects) Act 2009; Mental Health Act 2007; Conditions (Scotland) Act 2003; Sex Discrimination (Election Candidates) Act 2002; Trade Marks Act 1994; Crofters (Scotland) Act 1993; Education Act 1993 (repealed); Copyright, Designs and Patents Act 1988; Statute Law (Repeals) Act 1986; Agricultural Holdings Act 1986; Mental Health Act 1983; Patents Act 1977; Land Development Values (Compensation) Act (Northern Ireland) 1965; Registered Designs Act 1949; Patents Act 1949; Trade Marks Act 1938 (repealed 31.10.1994).

${ }^{8}$ See E J Gouvin 'Are There Any Checks and Balances on the Government's Power to Check Our Balances? The Fate of Financial Privacy in the War on Terrorism' (2005) 14 Temp Policy and Civil Rights Law Review 517,540 .

${ }^{9}$ See 'Glossary of Parliamentary Terms', where http://www.parliament.uk/site-information/glossary/sunsetclause.

${ }^{10}$ See Sofia Ranchordás, "Sunset Clauses and Experimental Regulations: Blessing or Curse for Legal Certainty?” [2015] 36 Statute Law Review 28, 30.

${ }^{11}$ See J Wallis, Constitution Making during State Building (2014, Cambridge University Press), 108.

${ }^{12}$ See Sabine Kurtenbach, "Introducing Institutional Reform: The Role of Sunset Clauses in Postconflict PowerSharing Arrangements" in Nadine Ansorg, and Sabine Kurtenbach, Institutional Reforms and Peacebuilding : Change, Path-dependency and Societal Divisions in Post-war Communities (2017, Studies in Conflict, Development and Peacebuilding).
} 
of "orderly transition" and consumer protection ${ }^{13}$; or even as an effective tool to threaten the independence of agencies. ${ }^{14}$

The provisions just below the previous example constitute a sunset clause in that they provide the extension of life of the legislation subject to parliamentary resolution:

(2) Her Majesty may by Order in Council provide that, instead of expiring at the time it would otherwise expire, this Act shall expire at the end of a period of not more than one year from that time.

(3) Such an Order may not provide for the continuation of this Act beyond the end of the year 2021.

(4) No recommendation may be made to Her Majesty in Council to make an Order under subsection (2) unless a draft of the Order has been laid before, and approved by a resolution of, each House of Parliament."

The example above is quite typical of the UK approach to sunset clauses. They are not headed by that term, and the table of contents of Acts does not include the term sunset clause. ${ }^{15}$ In fact, the term sunset clause is only found in the Explanatory Note (not the body of the legislation) of The Immigration and Police (Passenger, Crew, and Service Information) (Amendment) Order 2015. The actual provision (s2) states:

(3) After article 1(1), at the end, insert-

"(2) This Order shall cease to have effect at the end of the period of seven years beginning with the day on which the Immigration and Police (Passenger, Crew and Service Information) (Amendment) Order 2015 comes into force.”

Nudges to review an Act that expires, namely sunset clauses in substance but not in form, can also be traced in other UK General Acts, such as the Investigatory Powers Act 2016; the

\footnotetext{
${ }^{13}$ See Will Roberts, "Support for five-year 'sunset clause' on Legacy Commission” [2011] Professional Adviser 1.

${ }^{14}$ See Roberta Romano, "Does Agency Structure Affect Agency Decision-making: Implications of the CFPB's Design for Administrative Guidance” [2019] 36 Yale Journal on Regulation 273, 302.

${ }^{15}$ Sir Franklin Berman compared UK legislation to international treaties and remarked on the rarity of sunset clauses in UK legislation: see Sir Franklin Berman, "International Treaties and British Statutes" [2005] Statute Law Review 1, 6.
} 
Northern Ireland (Welfare Reform) Act 2015; the Enterprise and Regulatory Reform Act 2013; and the Interpretation Act 1978.

The empirical analysis of these Acts confirms that sunset clauses have been accurately defined as provisions who link the expiry of legislation to a qualitative review of its effectiveness. It also reveals that the term sunset clauses, which prevails in academic analyses, has not creeped its way into the body of legislation, at least not in the UK. Expry is the prevalent term irrespective of whether the revival of the Act is linked to post-legislative scrutiny or not. Yet, sunset clauses as drafting tools are used frequently in the EU and, with increasing popularity, the UK. ${ }^{16}$

Having defined the term, attention is due to the placement of sunset clauses in the text. The start and end of the life of legislation is a crucial communication to the users. It offers them an understanding of when their compliance with the legislation starts and when it finishes. The placement of start and expiry provisions has changed repeatedly in the last decade, from preliminary provision to final provision, and then back to preliminary again. In traditional drafting, especially in the common law, start and expiry provisions were considered merely technical carrying a message relevant and intelligible solely to lawyers and judges. They were classified as preliminary provisions, amongst the many technical ones placed at the beginning of the legislative text. In modern drafting, their importance for the users was recognised but they were demoted to the bottom of the text as final provisions, where they were joined by most traditionally preliminary provisions in a bid to offer the prime top spot in the body of the text to the main regulatory messages. The idea was the users have a limited attention span, which must be exploited to convey the substance of the regulatory request expressed in the legislative text. Any technical or secondary issues were transferred to the end of the text, available for the trained users who have interest and capacity to read them. In meta-modern legislative drafting published electronically, the primacy of their regulatory message is recognised but they remain at the end of the text: their regulatory message (namely the currency of the legislative text) is clearly demonstrated visually, for example by means of a green colour in the title of legislation to show that it is actually in effect.

\footnotetext{
${ }^{16}$ See HC Deb. I July 2003 Written Answer 217 from D Greenberg (Ed), Craies on Legislation (London, Sweet and Maxwell, 2004) 384, para. 10.2.4, note 7. Also see HM Government 'Better Regulation Framework: Guidance', 23 August 2018, https://assets.publishing.service.gov.uk/government/uploads/system/uploads/attachment_data/file/735 587/better-regulation-framework-guidance-2018.pdf.
} 
It is not unusual for simple brief commencement provisions, and rather more infrequently, even expiry provisions to be placed in preliminary provisions, as a reflection of the importance of their message to the user. But, unfortunately, the start and end date of legislation is often much more complex. In such cases, it would be counterproductive to upgrade a long list of various start and end dates in the beginning of the text, where they can indeed distract the user and steal away the precious few minutes of their limited attention span. Such lists must be placed in final provisions ${ }^{17}$ or, even better, in a schedule. A hanging clause in preliminary provisions directing the user to the end of the text or to the schedule could be an optimal compromise between the importance of the time message for the user and the technical nature of such provisions. And this constitutes the optimal placement for them: either briefly at the beginning of the text or at the bottom with a hanging provision declaring the primacy of their message.

Having explored their definition and placement, it is time to turn our attention to their effect. There is a question as to whether Acts including sunset clauses need to be formally repealed after their set expiry date. Constitutionally, there is no doubt that the Act dies as soon as the end date occurs. Thus, from a substantive law perspective, a formal express repeal of the dead legislative text is unnecessary and even superfluous. But there is a question of best drafting practice. Although the repeal is not necessary from a legal perspective, nonetheless clarity is best served with an express repeal. The added value of this method is that the Act disappears from subsequent reprints of the statute book. ${ }^{18}$

Having discussed the definition, placement, and effect of sunset clauses, attention must now be turned to their usage. Even in a more traditional approach to the innovative requirement

1735 Commencement

(1) Subject as follows, this Act comes into force on such day as the Secretary of State may by order appoint; and different days may be appointed for different purposes.

(2) Section 1(1) so far as it inserts the new section 62B, sections 4, 7, 9, 16, 19, 26, 32 and 33, this section and section 36, and Schedules 2 and 4, come into force on the day on which this Act is passed.

(3) Sections 11, 12, 17, 18, 29 and 30 come into force at the end of two months beginning with the day on which this Act is passed.

(4) Section 21(4) to (6) come into force on such day as the Scottish Ministers may by order appoint; and different days may be appointed for different purposes.

(5) The Scottish Ministers may by order make such transitional, transitory or saving provision as the Scottish Ministers consider appropriate in connection with the coming into force of section 21(4) to (6).

(6) The Secretary of State may by order make such transitional, transitory or saving provision as the Secretary of State considers appropriate in connection with the coming into force of any other provision of this Act.

(7) Power to make an order under subsection (5) or (6) includes power to make different provision for different purposes.

See Growth and Infrastructure Act 2013, Section 35.

${ }^{18}$ See A L Diamond 'Repeal and Desuetude of Statutes' (1975) 28 Current Legal Problems 107, 124. 
for end dates by default, sunset clauses are necessary in four distinct types of legislation. First, legislation in stages can be useful in cases of controversial issues: for example, liberalising abortion in a deeply religious society may lead to a useless addition to the statute book without an incremental approach; liberalisation can start by allowing abortion exclusively where the mother's life is at risk, or where the embryo is a product of a criminal act; it can then expand to abortion up to 9 weeks of gestation; and then it can proceed further. This incremental approach is served very well by means of a staggered start and end date of the intermediate regulatory regimes. Second, legislation that is experimental or whose benefits are speculative or unpredictable would require an end date: throwing the legislative text in the statute book for a limited period of time can allow the text the opportunity to produce the desired regulatory results, thus earning its place within the statute book. Third, legislation responding to a short term need requires an end date: classical example of this would be legislation offering aid to citizens suffering from extreme natural phenomena. And fourth, authorisations to use emergency powers always come with an end date: they are a break from constitutional normality, and are tolerated only for a well defined short period of time.

A common response to sunset clauses is that they serve little purpose. After all, legislation knows no end. We legislate for an indefinite period of time, or at least this is what we continue to profess, even though in the UK the average lifecycle of legislation sits at only 20 years.

Whatever response one arrives to in the debate of sunset clauses against the longevity of legislation seems academic. And this is because sunset clauses serve more than murderers of allegedly immortal laws. They can serve as an effective tool for enhancing legislative effectiveness and, ultimately, regulatory efficacy. ${ }^{19}$

\section{Sunset clauses as contributors to legislative effectiveness ${ }^{20}$}

\footnotetext{
${ }^{19}$ For an analysis of the benefits of sunset clauses see J E Finn 'Sunset Clauses and Democratic Deliberation: Assessing the Significance of Sunset Provisions in Antiterrorism Legislation' (2009-2010) 48 Columbia Journal of Transnational Law 442, 447.

${ }^{20}$ The analysis of effectiveness has been developed in my recent work but originates mainly from Helen Xanthaki, on Transferability of Legislative Solutions' in C. Stefanou and H. Xanthaki (Eds) Drafting Legislation. A Modern Approach (Ashgate 2008) 1-18, 17; H. Xanthaki, Drafting Legislation. Art and Technology of Rules for Regulation (2014) 7.
} 
Legislation constitutes a tool for regulation and, as such, it should be viewed as a part of the legislative process, which in turn is a part of the policy process. From an instrumental, functional perspective, legislation is one of the tools available to governments in their attempt to regulate behaviours in response to undesirable social phenomena. Viewing legislation as a regulatory tool leads easily into the definition of a good law. A good law is simply one that is capable of contributing to the production of the desired regulatory results. ${ }^{21}$ Let us explore this further.

The ultimate goal for regulation is efficacy, defined as the extent to which regulators achieve their goals. Regulatory efficacy is a factual quality, a response to the factual question whether the regulatory exercise has indeed produced the results envisaged by the policy makers. On that basis, efficacy is a quality that presents post-legislatively. It requires not just the passing of the legislation but also its coming to effect. It requires adequate post-legislative time to reveal itself. And it is dependent on the holistic and harmonious performance of all actors in the policy process. All of them need to play their part well, in order to allow efficacy to blossom and then slowly to flower. Policy officers need to identify the correct, concrete and accurate regulatory goal, one that is not too general to become impossible to achieve but at the same time not too narrow to be uninspiring or unworthy of resources. Legal officers and law reformers need to share understanding of the regulatory aims, translate them into law reform, and identify the effect that this reform might have on the rest of the legal system. And drafting officers need to share understanding of the regulatory and law reform agenda, and identify the most appropriate legislative tool to make efficacy happen. If any of these three levels is flawed, efficacy can only be achieved haphazardly.

Legislative analysis focuses on legislative effectiveness, namely on the production of a legislative text that can contribute to regulatory efficacy. Effectiveness measures the capacity of the legislative text to express the regulation in a manner that can allow it to achieve efficacy. But successful legislative expression is only relevant in the presence of regulatory aims that actually address the social phenomenon in question and that are achievable by means of the regulatory solutions put forward by policy officers. A wonderfully drafted law cannot possibly contribute to the production of the desired regulatory results, if the choice of regulatory mechanism is haphazard and consequently doomed to miss its target from the word go. Just as

\footnotetext{
${ }^{21}$ H. Xanthaki, 'Drafting Manuals and Quality in Legislation: Positive Contribution towards Certainty in the Law or Impediment to the Necessity for Dynamism of Rules' [2010] Legisprudence IV 2115
} 
efficacy, effectiveness proves itself post-legislatively. But, in view of the inherent difficulty of measure capacity accurately, its scrutiny is also inherently fluid. ${ }^{22}$ Despite its fluidity and relativity, effectiveness is a solid criterion of legislative quality. It applies to all types of legislative instruments. If the purpose of legislation is to serve as a symbol, then effectiveness becomes the measure of achieved inspiration of the users of the symbol legislation. If legislation is to be used as a ritual, effectiveness takes the robe of persuasion of the users who bow down to its appropriate rituality. If legislation is functional, effectiveness measures the extent of the production of the desired regulatory results. ${ }^{23}$

Legislative effectiveness is nurtured by clarity, precision, and unambiguity of legislative expression. Clarity is the quality of being clear and easily perceived or understood. Precision is the exactness of expression or detail. Unambiguity is certain or exact meaning: semantic unambiguity requires a single meaning for each word used, whereas syntactic unambiguity requires clear sentence structure and correct placement of phrases or clauses.

Clarity is nurtured by easified language and, where appropriate, gender inclusive language. Easified language pitches legislative communication to the level of legal and subjectrelated sophistication of the users of the specific legislative text. Easification refers to choice of words, of syntax, of structure, and of context. Gender inclusive language eliminates referents of gender in legislative expression.

Where do sunset clauses come into this paradigm of legislative quality? Sunset clauses serve as tools of clarity, precision and unambiguity; and as tools for efficacy. Let us explore the two angles separately.

Sunset clauses convey clearly, with precision, and unambiguously when the legislation will end. They manage to convey one of the most complex and, until recently, vague regulatory messages, namely that of the precipitated end of the legislation. This allows users to organise their affairs accordingly. Thus, they serve legal certainty and, as such, the rule of law. ${ }^{24}$

\footnotetext{
${ }^{22}$ See Klaus Ziegert, "The Theory and the Measurement of the Effectiveness of Legislation" [1983] 14 Berichte und Kritik Rechtstheorie 204, 240-246.

${ }^{23}$ See John Dickinson, "Legislation and the Effectiveness of Law" [1931] American Bar Association Journal $645,651$.

${ }^{24}$ On a full analysis of time in legislation and the rule of law, see Sofia Ranchordás, "The International Rule of Law Time After Time: Temporary Institutions Between Change and Continuity" [2014] The Netherlands Yearbook of International Law 67-91.
} 
In doing so, sunset clauses also let the user into the regulatory plan. They offer them the knowledge that this piece of legislation is introduced under the condition that it will be assessed in a set period of time. This contextual knowledge may be instrumental in instigating the behavioural changes sought by the regulators. When legislation is experimental, harsh to implement, or even seemingly nonsensical, users are encouraged to still comply with it in the comfort of the knowledge that its effectiveness will be reviewed and the legislation terminated, if justified. ${ }^{25}$

Moreover, this invitation to participate in the regulatory game reassures users that legislation is passed after due consideration and only if needed, that its effect is indeed monitored closely, and that action will be taken to remove or reinstate it, as proven appropriate by post-legislative scrutiny exercises. ${ }^{26}$ And so, sunset clauses contribute to the reversal of users' mistrust to legislation, to the law, and to authority. This in turn feeds into effectiveness, as it supports an environment of regulatory compliance nurtured by trust.

Finally, sunset clauses enhance legislative quality within the statute book as the whole body of legislative texts by cleaning it from legislation that served its purpose and can now go or legislation that missed its regulatory targets. ${ }^{27}$ Sunset clauses can be the optimal answer to the labyrinth of legislative texts that plague the statute book with complexity. In fact, they can be the civil law equivalent to law revision in the common law. ${ }^{28}$

Having identified the role of sunset clauses as contributors to effectiveness and, ultimately, efficacy, let us explore their role as guardians of legislative quality.

\section{Sunset clauses as guardians of legislative quality ${ }^{29}$}

\footnotetext{
${ }^{25}$ And parliamentarians maybe more inclined to pass the legislation: see Tom Ginsburg et al, "Libertarian Paternalism, Path Dependence, and Temporary Law" [2014] 81 University of Chile Law Review 291, 337.

26 "Fast regulatory solutions (or at least faster than lasting legislation) are offered because sunset clauses and experimental legislation have the potential to gather consensus more easily than permanent legislation": see Sofia Ranchordas, "Innovation-Friendly Regulation: The Sunset of Regulation, the Sunrise of Innovation" [2015] 55 Jurimetrics 201, 217.

${ }^{27}$ See Lewis Davis, "Review Procedures and Public Accountability in Sunset Legislation: An Analysis and Proposal for Reform" [1981] 33 Administrative Law Review 393.

${ }^{28}$ See Wim Voermans, Chris Moll, Nico Florijn and Peter Van Lochem, "Codification and Consolidation in the European Union: A Means to Untie Red Tape” [2008] 29 Statute Law Rev 65, 81.

${ }^{29}$ Xanthaki's paradigm of enlightened legislative scrutiny is fully developed in H. Xanthaki, "An enlightened approach to legislative scrutiny: focusing on effectiveness" European Journal of Risk Regulation [2018] 431 434.
} 
Guarding legislative quality is not a simple or mechanical task. The fluidity and relativity of legislation as a product invites a qualitative assessment of legislative quality, ${ }^{30}$ one that is equally flexible and fluid. But, at the same time, the accurate assessment of legislative quality requires a concretely set test that can block possible manipulation in order to produce "the right" results. ${ }^{31}$

The prevalent method of evaluating effectiveness, as the criterion of legislative quality, is Mousmouti's effectiveness test. It proposes an assessment of objectives, content, context, and results. ${ }^{32}$ This innovative methodology of legislative quality has value, in that it is original as the first test of effectiveness, and it is innovative as the first concretization of the effectiveness concept. However, its admittedly useful departmentalization into objectives context, clauses, and results encapsulates a collateral danger: that of accentuating the already fragmented approach to legislative scrutiny into sub-exercises of evaluation conducted by the various regulatory actors on their own task in the regulatory effort. But fragmentation of legislative scrutiny is inherent not only in Mousmouti's effectiveness test but also, perhaps even more so, in current methodology of impact assessments and of cost benefit analyses. ${ }^{33}$ These are excellent in assessing fragments of the mosaic that is legislation and regulation. ${ }^{34}$ But legislation is not fragmented, and neither is regulation. ${ }^{35}$

\footnotetext{
${ }^{30}$ The link between quality and scrutiny is detailed in OECD, "Implementing Administrative Simplification in OECD Countries: Experiences and Challenges", http://www.oecd.org/dataoecd/0/37/37026688.pdf (accessed 9 June 2019); and Dirk Meulen, "The Use of Impact Assessments and the Quality of Legislation" [2013] 1 Theory and Practice of Legislation 305.

${ }^{31}$ See Elena Griglio, "Post-Legislative Scrutiny as a Form of Executive Oversight Tools and Practices in Europe" [2019] 21 European Journal of Law Reform 118, 122.

${ }^{32}$ See Maria Mousmouti, "Operationalising Quality of Legislation through the Effectiveness Test" [2012, 6:2 Legisprudence 201; also see Maria Mousmouti, "Effectiveness as an Aspect of Quality of EU Legislation: Is It Feasible" [2014] 2 Theory and Practice of Legislation 309; and Maria Mousmouti, "Making Legislative Effectiveness an Operational Concept: Unfolding the Effectiveness Test as a Conceptual Tool for Lawmaking" [2018] 9 European Journal of Risk Regulation 445.

${ }^{33}$ See, for example, World Bank Group, Better Regulation for Growth: Governance Frameworks and Tools for Effective Regulatory Reform: Regulatory Quality Indicators (2010, World Bank).

${ }^{34}$ Mousmouti lists the sets of indicators of regulatory quality as follows: "The OECD Product Market Indicators measure the extent to which regulatory environments enable competition; the World Bank Indicators of governance and institutional quality cover the quality of regulatory outcomes within the broader framework of governance; the World Bank Doing Business Indicators focus on business related regulations in different areas based on information from both official sources as well as through the perceptions of government agencies and law firms; the OECD Indicators of government capacity to produce high quality regulations record the content of regulatory policies, quality tools, institutional arrangements, dynamic aspects and performance or outcome indicators. Further, indicators are used by governments either for conduct studies aiming to assess whether established practices were followed, impact studies that focus on the impact on decision making and accuracy studies which assess the quality of ex ante regulatory analysis by comparing predicted versus actual impacts. The OECD develops indicators for regulatory management systems." See Maria Mousmouti, op.cit., 198. ${ }^{35}$ This reflects the holistic description of effectiveness as a concept that brings together policy, law, and drafting. See Sir Stephen Laws, "Legislation and Politics" in D. Feldman, Law in Politics, Politics and Law (2013, Hart Publishers, Oxford), 90.
} 
In order to reflect the overall patchwork of regulation holistically, the assessment of legislative quality must recognize the interdependence of the values of regulatory efficacy, legislative effectiveness, clarity/precision/unambiguity, easification and gender inclusivity. Such a holistic assessment invites for an all-embracing evaluation of legislation as a tool for regulation, bringing together the currently fragmented evaluations of efficacy, effectiveness and cost-efficiency. It requires contribution from all actors in the policy/regulatory process. ${ }^{36}$

Such a holistic evaluation exercise is useful both at a pre-legislative stage, as a means of confirming the possible capacity of legislation to lead to efficacy, and also at a postlegislative stage, as a means of confirming whether the legislation did actually lead to regulatory efficacy. ${ }^{37}$

And it will involve questions related to the whole policy/regulatory process, as effectiveness is not about words and legislative expression. It arches over legislative expression (words and syntax), structure of the legislative text, context within the statute book, layout of publication, and explanatory materials. This holistic, overarching concept of effectiveness reflects and is nurtured by the holistic concept of legislative drafting and legislative scrutiny.

Thus, at a pre-legislative scrutiny exercise, effectiveness demands answers to the following tests, all contributing to an answer to the question whether the legislative text is capable of producing the desired regulatory results:

1. Testing the conceptual effectiveness of the regulatory concept

a. Which are the desired regulatory results?

b. How can they be measured?

c. Within how long are they to be achieved?

d. Can the selected enforcement mechanisms produce the desired regulatory results within the set times?

e. Can the text be implemented without stumbling on socio-legal hurdles?

2. Testing the effectiveness of the legislative concept

a. What is the legal mischief and how is it connected to the desired regulatory goals?

\footnotetext{
${ }^{36}$ On the need for better scrutiny of concrete regulatory results, see Paul Stephenson, "Why Better Regulation Demands Better Scrutiny of Results" [2017] European Journal of Law Reform 97.

${ }^{37}$ M. Zamboni, "Legislative Policy and effectiveness: a (small) contribution from legal theory" (2018)

European Journal of Risk Regulation 6.
} 
b. Is this addressed by non-legislative means in the jurisdiction?

c. How is the new legislation expected to address the mischief?

3. Testing the effectiveness of the legislative communication

a. Which are the main groups of possible users of the text?

b. What level of awareness of the topic do they have?

c. What is their level of legal awareness?

d. What questions does each group ask?

e. Does the current structure provide accessible answers the specific questions of each of the user groups?

f. Does the current structure facilitate the unhindered identification of the relevant answers?

4. Testing the effectiveness of legislative expression

a. Does the language of each provision communicate its message to each of the intended user groups in a manner that they can understand (topic and law)?

b. If this is difficult, what tools have been used to address complexity?

i. Examples

ii. Definitions or interpretation

5. Testing the effectiveness of presentation

a. Is the layout simple?

b. Does the text refer the user to relevant provisions, perhaps via:

i. Hyperlinks

ii. Explanatory notes

6. Testing the effectiveness of monitoring

a. How often

b. With which results?

The elements of this effectiveness test function consecutively. It is a concept of "sudden death": if the text fails one test, it fails automatically the ones below it. So, the exercise stops at the moment of failure at any point in the scrutiny process. Failure in one test is evidence of ineffectiveness of the text.

At a post-legislative scrutiny exercise, effectiveness demands answers to the following corresponding questions in a consecutive order:

1. Which were the desired regulatory results pursued by means of the legislation? 
2. Has the selected regulatory mechanisms led to the desired regulatory results, as evidenced by empirical data ${ }^{38}$ ?

3. Has the legal mischief been addressed by new legislation, as evidenced by data ${ }^{39}$ ?

4. Were there any issues arising from the choice of legislative expression and how can these be addressed?

5. Is efficacy achieved?

6. If not, was the legislation effective as evidenced by 3 and 4 ?

7. If not, how can the issues be addressed: repeal, repeal and re-enact, amend the legislation?

8. In how many years does the legislation need to be re-evaluated?

This type of scrutiny claims value in that it is original as the first holistic exercise of legislative scrutiny; and it is effective as it contributes greatly to a closure of the current gap between legislative intent and legislative effect. ${ }^{40}$ Xanthaki's scrutiny method forces policy officers to reveal concrete regulatory aims and their preferred method of achieving them. In turn, this forces law reformers to translate the regulatory aims to mechanisms of law reform, namely changes in the law. Which forces, and allows, drafters to express in an effective manner.

In doing so, Xanthaki's method of legislative scrutiny offers Parliament and its legislators an insight into what the legislation requires to perform, how it is hoped that this will be achieved, and on what basis the assessment of the success of the legislative text will take place at the post legislative stage. Parliament can then use this data to evaluate the effectiveness of the legislative text both as part of their scrutiny when passing the legislation but also as part of their scrutiny of the legislation in legislative reviews. ${ }^{41}$

It is precisely here that sunset clauses can serve as guardians of legislative quality. By providing for the end of the legislation, unless Parliament extends its duration, they empower Parliament to impose a full and meaningful post-legislative exercise ${ }^{42}$ after a set number of

\footnotetext{
${ }^{38}$ O. D. Oliver-Lalana 'Due Post-Legislative Process? On the Lawmakers' Constitutional Duties of Monitoring and Revision in K. Messerschimdt \& A. D. Oliver-Lalana (Eds) Rational Lawmaking under Review. Legisprudence According to the German Federal Constitutional Court (Springer 2016) 259.

39 J. Rachlinski 'Evidence-Based Law' (2011) 96 Cornell Law Review 901-923, 910.

${ }^{40}$ E R Beerworth 'The Evaluation of Legislation' in R Tomasic (ed), Legislation and Society in Australia (Allen and Unwin, 1980) 66, 68.

${ }^{41}$ For an analysis of post-legislative scrutiny in the UK, see Tom Caygill, "A Tale of Two Houses: PostLegislative Scrutiny in the UK Parliament" [2019] 21 European Journal of Law Reform 87.

42 See Lydia Clapinska, "Post-Legislative Scrutiny of Acts of Parliament" [2006] 32 Commonwealth Law Bulletin 19, 198.
} 
years, ${ }^{43}$ on the basis of which Parliament can either passively allow the legislative text to die or pro-actively extend its life further either as it originally stood or after amendments. Let us explore this further. ${ }^{44}$

Since legislation is a tool for regulation, its performance is increasingly judged against a concrete set of tangible measurable criteria for post-legislative scrutiny. These can, and increasingly are used, for periodic review of legislation. Providing them in legislation by means of a new genre of purpose or objectives clauses combined with a sunset clause for action resulting from periodic review would not just reflect but mainly enhance the closure of the life cycle of regulation and legislation. Forcing government departments to conduct a postlegislative scrutiny exercise as a means of persuading Parliament that the legislative text is effective $^{45}$, and can continue its life, is a proactive way of returning regulators to the efficacy and effectiveness agenda. Currently post-legislative review is assigned to government departments, albeit without the persuasive mechanism of a sunset clause. This can result to haphazard post-legislative scrutiny. Using sunset clauses as a tool supplementing, and strengthening, post legislative scrutiny would greatly enhance legislative quality.

Sunset clauses enhance legislative quality not just within the legislative text but also at the level of the statute book. They do so by automatically cleaning the statute book every 3 or 5 years, depending on the duration of legislation. It makes perfect sense for end provisions to be inserted in legislation as standard, allowing for exceptions only where the possibility of a lack of legislative regulation if the legislation dies unintentionally may create regulatory chaos or unease. In the EU sunset clauses are part of the Smart Regulation agenda, and are becoming increasingly frequent. But, then again, sunset clauses on their own are not effective regulatory review weapons: they need to be supplemented by meaningful post legislative scrutiny exercises undertaken on the basis of measurable criteria.

The starting point for post-legislative scrutiny is, what were the original desired regulatory results. If the regulatory results have been produced, the capacity of the legislative text to contribute to the regulatory effort is proven. If the results are not there, the social

\footnotetext{
${ }^{43}$ See contra Nicola McGarrity, Rishi Gulati, and George Williams "Sunset Clauses in Australian anti-Terror Laws" [2012] 33 Adelaide Law Review 307, 308, who report that sunset clauses are accused of providing a convenient political excuse for shortcutting initial parliamentary debate about controversial legislation, thereby postponing the substantive debate until the legislation comes up for expiry or renewal.

${ }^{44}$ See Lewis Anthony Davis, "Review Procedures and Public Accountability in Sunset Legislation: An Analysis and Proposal for Reform" [1981] 33 Aministrative Law Review 393, 395.

${ }^{45}$ See P Suber, 'The paradox of self-amendment: a study of law, logic, omnipotence, and change, 1998, http://www.earlham.edu/-peters/writing/psa/sec 14.htm, 14.
} 
scientists participating in the scrutiny exercise need to identify the error. If the error lies with the choice of the regulatory mechanism, then alternative means of regulation can be sought and the legislation can be repealed; or the legislation can be supported by additional regulatory mechanisms. If the problem lies with the content of the legislation, the substantive lawyers must investigate the effects of the legislation to the legal system, and identify the continuing mischief. The mischief can be a result of a legal or drafting error. If the legal system corrected itself in response to the legislation, the lawyers must identify how this occurred and how to prevent it from happening.

Although sunset clauses cannot by themselves guarantee legislative quality, they do serve as the guardians to the portal that is holistic and effective legislative scrutiny. They start the ball rolling by ensuring first that post-legislative scrutiny will take place for legislation that will continue to be in effect after its expiry date; and second that Parliament has an active role to play in the scrutiny of post-legislative scrutiny. Of course, sunset clauses cannot force the executive to extend the legislation, nor interest groups to campaign for or against $\mathrm{it}^{46}$, nor the legislature to scrutinise effectively ${ }^{47}$ and avoid using them as a snooze button to democracy. ${ }^{48}$ And nor should they. They are simple tools that open the gates to a possibility of effective postlegislative assessment. But, combined with concrete purpose clauses, they can be mighty guardians of legislative quality.

\section{Conclusions}

This chapter set out to shed a new light to sunset clauses, by departing from the analysis of their constitutional role and focusing on their legislative role instead. The hypothesis was that sunset clauses contribute to legislative effectiveness and regulatory efficacy. The methodology chosen was to define and analyse sunset clauses as a legislative tool; to analyse legislative effectiveness as a criterion for legislative quality, and to identification of the role of sunset clauses as contributors to legislative quality; to analyse Xanthaki's enlightened scrutiny test,

\footnotetext{
${ }^{46}$ See Forrest Maltzman and Charles Shipan, "Change, Continuity and the Evolution of the Law" [2008] 52 American Journal pf Political Science 252, 254.

${ }^{47}$ For example, Parliament may lack the capacity to question effectively a Departmental review of legislation: see Editorial, "Post-legislative scrutiny" [2006] 27 Statute Law Review 1, 3.

${ }^{48}$ For an exhaustive analysis of sunset clauses and snoozing democracy, see Antonia Kouroutakis and Sofia Ranchordas, "Snoozing Democracy: Sunset Clauses, De-Juridification, and Emergencies" [2016] 25 Minessota Journal of International Law 29, 35.
} 
and to identify the role of sunset clauses as guardians of legislative quality. And to prove that sunset clauses are both contributors to legislative quality and guardians of regulatory efficacy.

Sunset clauses were defined as a sub-category of expiry provisions, which in turn are a sub-category of duration provisions. Sunset clauses are complex expiry provisions in that they convey the end of life of legislation at a set time, and they allow extension of that life subject to parliamentary evaluation of the effectiveness of legislation.

Sunset clauses are placed at the end of the legislative text but combined either with a visual indication of the currency of the legislative text, or a hanging provision at the start of the text. This reflects the balance between the primacy of their regulatory message and the need to keep the prime time of the users' attention for the main regulatory communication.

From a legislative perspective, and against legality or constitutionality perspectives, the express repeal of the expired legislative text is needed to clarify the status of the text as current or expired.

In traditional drafting, sunset clauses are necessary in four distinct types of legislation, namely in controversial laws; in experimental legislation; in legislation responding to a shortterm need; and in authorisations of emergency powers. But sunset clauses are equally useful in all types of legislation, because they can serve as an effective tool for enhancing legislative effectiveness and, ultimately, regulatory efficacy.

Sunset clauses enhance legislative quality because they can serve as tools of clarity, of precision and of unambiguity; and as tools for regulatory efficacy. As sunset clauses convey clearly, with precision, and unambiguously when the legislation will end, they promote legal certainty. And they consequently strengthen the rule of law. In disclosing their end clearly, precisely, and unambiguously, sunset clauses reveal the regulatory plan to the user, thus instigating increased compliance and trust to legislation, to the law, and to authority. This feeds back into effectiveness and efficacy. Finally, sunset clauses serve as periodic cleaners of the statute book taking the role of small scale focused law revision.

Sunset clauses also serve as guardians of legislative quality. In Xanthaki's holistic scrutiny method, sunset clauses empower Parliament to impose a full and meaningful postlegislative exercise after a set number of years, on the basis of which Parliament can either passively allow the legislative text to die or pro-actively extend its life further either as it originally stood or after amendments. Thus, sunset clauses manage to single-handedly force 
the executive to evaluate the legislation, to nudge Parliament to undertake substantive and effective post-legislative scrutiny, and the statute book to rid itself from legislation that proved unworthy of its place in the statute book (either by omission to extend or by failure to pass parliamentary scrutiny).

The conclusion of this analysis is that sunset clauses are certainly worth considering as a standard provision in most legislative texts. However, as is the case with all things drafting, they do carry with them some risk. The obvious problem is the risk of an unintentional regulatory gap. It is possible to imagine a situation where the executive is not alert to the imminent expiry of the legislation and do not move to extend, the legislation expires, and regulation of this area stops without warning, without provision, and without any replacement. ${ }^{49}$ One could argue that the risk of unintended regulatory gaps may, at least in certain cases, outweigh the benefits of a sunset clause. Of course, this is not a risk that can be dismissed generally at an abstract level: the threat is present, and, in certain cases, could lead to regulatory chaos. But, drafting is a series of dilemmas. Thus, the introduction of a sunset clause requires a balancing exercise between the benefits of the clause against the risk of a potential unintended regulatory gap. Criteria for making that choice could be the topic of the regulation, the imperative (or not) need for constant regulation in the field, the possible ability of surrounding legislation or even future self-regulation to cover the area of activity involved, or the agility of executive and legislature in the jurisdiction in question to act quickly and effectively, should the need occur. The decision can only be ad hoc and so the danger of possible unintended regulatory gap cannot stand in the way of sunset clauses as a tool for legislative effectiveness and regulatory scrutiny.

An additional weakness of the otherwise mighty sunset clauses is their dependence upon the regulatory sophistication of the jurisdiction that they serve. In order for sunset clauses to perform satisfactorily, they require regulators aware of their regulatory aims; regulators able and willing to express their regulatory aims as policy goals and to share them with the drafters; legal officers that have the capacity to express these policy goals in law reform terms; and drafters or lawmakers that can translate law reform terms to sophisticated, concrete, and effective modern purpose/objectives clauses. In other words, for sunset clauses to work

\footnotetext{
${ }^{49}$ See Paco Francoli, "Bills Need Sunset Clauses, Urges Grit Senator Banks: 'Some Pieces of Legislation Are Sort of Sitting There Almost Hanging over Our Heads'.” [2003] The Hill Times 677.
} 
effectively, they need to feed and flourish from a sophisticated regulatory environment, dedicated to regulatory efficacy, to legislative effectiveness, and to economic cost-efficiency.

This last paragraph seems to negate the praises sung for sunset clauses in this chapter. Indeed, it is questionable whether sophisticated regulatory environments exist, let alone whether they are allowed to function in the ideal scenario described above. One would expect that they tend to bow down to pressures of expediency and political compromise. But political reality cannot take away from the fact that sunset clauses have already been useful tools for legislative effectiveness and regulatory efficacy. And thus it seems that the current immature regulatory environment against which they are set does not hinder their value. If anything, it actually enhances it, by showcasing how sunset clauses can contribute to efficacy and effectiveness. Who knows what sunset clauses can achieve within a mature regulatory environment, strengthened further by equally concrete and holistic purpose/objectives clauses.

This chapter suggests that it is worthwhile giving them, and purpose/objectives clauses, a chance to close the current gap in the cycle of regulation. 